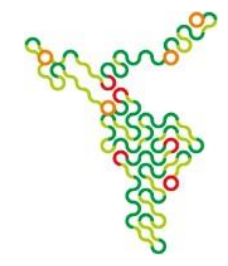

\title{
A PRESENÇA DO IDOSO NO AMBIENTE UNIVERSITÁRIO: DO DIREITO A EDUCAÇÃO A REINSERÇÃO SOCIAL
}

\author{
Thânia Mara Kaminski Jacon ${ }^{1}$ \\ Paola Andressa Scortegagna ${ }^{2}$ \\ Rita de Cássia da Silva Oliveira ${ }^{3}$
}

\begin{abstract}
Resumo: O contínuo processo de envelhecimento do ser humano e sua presença na sociedade garantem a necessidade de discussões que permitam a ampliação dos conhecimentos sobre o tema envelhecimento. A importância de ações, especialmente educativas, voltadas aos idosos visam garantir a efetivação dos direitos dessa parcela significativa da população. A educação permanente assegura a participação desses sujeitos, tanto na vida social quanto cultural, permitindo que as relações interpessoais se aperfeiçoem e reflitam na melhora da qualidade de vida. Nesse sentido, as Universidades Abertas para a Terceira Idade (UATI) desempenham um papel importante, assegurando o contínuo desenvolvimento dos sujeitos e permitindo novas conquistas que refletem na superação individual e na inserção do idoso no ambiente universitário. A UATI da Universidade Estadual de Ponta Grossa (UEPG) desempenha, desde 1992, ações educativas que contribuem com o desenvolvimento e valorização dos idosos. Com o objetivo de analisar a importância das ações voltadas aos idosos no espaço universitário e os resultados desse programa, a pesquisa qualitativa realizada apontou o crescimento significativo do número de idosos na UATI/UEPG, tornando-auma referência na região em que atua. Além disso, as possibilidades de construção de novos conhecimentos, das transformações conceituais acerca da terceira idade e do papel fundamental da educação como meio de reinserção social foram alguns resultados obtidos nessa pesquisa.
\end{abstract}

Palavras-chave: Educação na Terceira idade; Reinserção social; Aprendizagem; Educação não formal.

\section{THE PRESENCE OF THE ELDERLY IN THE UNIVERSITY ENVIRONMENT: FROM THE RIGHT TO EDUCATION TO SOCIAL REINSERTION}

\begin{abstract}
The continuous process of aging of the human being and his presence in society guarantee the need for discussions that allow the expansion of knowledge on the theme of aging. The importance of actions, especially educational, aimed at the elderly is aimed at guaranteeing the realization of the rights of this significant part of the population. Continuing education ensures the participation of these subjects, both in social and cultural life, allowing interpersonal relationships to be improved and reflected in the improvement of the quality of life. In this sense, Open University for the Elderly (UATI) play an important role, ensuring the continuous development of the subjects and allowing new achievements that reflect in the individual overcoming and insertion of the elderly in the university environment. Since 1992, the UATI of the Ponta Grossa State University (UEPG) has
\end{abstract}

\footnotetext{
${ }^{1}$ Mestranda em Educação, Universidade Estadual de Ponta Grossa (UEPG), Ponta Grossa, Paraná, Brasil.

${ }^{2}$ Doutora em Educação, Universidade Estadual de Ponta Grossa (UEPG), Ponta Grossa, Paraná, Brasil.

${ }^{3}$ Doutora em Educação, Universidade Estadual de Ponta Grossa (UEPG), Ponta Grossa, Paraná, Brasil.
} 


\section{Universidade do Extremo Sul Catarinense \\ Revista Ibero-Americana de Humanidades, Ciências e \\ Educação \\ unesc

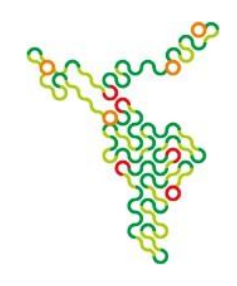

carried out educational activities that contribute to the development and enhancement of the elderly. With the objective of analyzing the importance of actions aimed at the elderly in the university space and the results of this program, the qualitative research carried out pointed out the significant increase in the number of elderly in the UATI / UEPG, making it a reference in the region in which it operates. In addition, the possibilities of constructing new knowledge, conceptual transformations about the third age and the fundamental role of education as a means of social reintegration were some results obtained in this research.

Keywords: Education in the Third Age; Social reinsertion; Learning; Non-formal education.

\section{Introdução}

O fenômeno do envelhecimento humano tem gerado discussões nos mais diferentes âmbitos, sempre com a finalidade de possibilitar que essa população possa usufruir da vida com maior qualidade.

Para Oliveira (2002, p.38) "o envelhecimento deve ser encarado como um processo natural e não como uma doença terminal." Ainda que a visão que se tem do idoso seja de um sujeito improdutivo, imagem essa culturalmente aceita no Brasil, é necessário trabalhar o envelhecimento como mais uma etapa da vida, na qual existem desafios mas eles não simbolizam impossibilidade.

No Brasil, a expectativa de vida subiu para 75,8 anos (IBGE, dez.2017). Na prática, isso demonstra que a população está envelhecendo, justificando assim os movimentos de discussão sobre o tema do envelhecimento humano. O envelhecimento populacional pode ser atribuído a um conjunto de fatores: qualidade de vida, avanço na medicina, políticas de saúde e bem-estar, decréscimo da natalidade, entre outros.

Ao propor ações embasadas nos princípios educacionais se denota importância tanto no aperfeiçoamento dos saberes (e na construção de novos) como nas relações interpessoais que alicerçam o sujeito social, refletindo na melhora da qualidade de vida e empoderamento do idoso.

Na Constituição Federal de 1988, quando o número de idosos era inferior ao atual, se refletia e projetava sobre a importância de preservar a cidadania e o resgate (ou manutenção?) da dignidade desses cidadãos, destacando o respeito aos seus direitos, sendo estes imprescindíveis e inalienáveis (SANTIN, 2007). O artigo 205 dessa Constituição diz que a educação - direito de todos e dever do Estado e da família - deve visar o pleno desenvolvimento da pessoa humana, seu preparo para o exercício da cidadania e sua qualificação para o trabalho. Não há menção explícita ao idoso mas ele 


\section{Universidade do Extremo Sul Catarinense \\ Revista Ibero-Americana de Humanidades, Ciências e \\ Educação \\ unesc

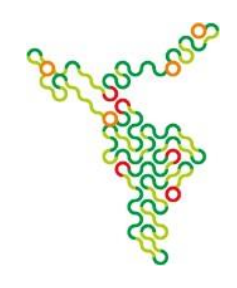

se insere na modalidade de Educação de Jovens e Adultos, no entanto as especificidades que envolvem seu processo de aprendizagem exigem ações diferenciadas.

Já no Estatuto do Idoso (lei 10.741/03) as especificações são claras e pertinentes, elucidando aspectos como o direito do idoso à educação, cultura, esporte, lazer, espetáculos, diversões, serviços e produtos que respeitem suas condições (Art.20). Outro destaque está no incentivo à criação das Universidades Abertas para a Terceira Idade, reforçando a garantia à educação com adequação de currículos, metodologias e material didático (Art.21).

O incentivo à educação reforça a importância da cidadania, da participação nos âmbitos políticos, civis e sociais. A educação permanente permite ao idoso assumir o papel de ator social, participativo e atuante no meio em que está inserido. A educação e o trabalho desenvolvido pelas Universidades Abertas para a Terceira Idade ganham destaque nesse processo.

\section{Educação permanente e as Universidade Abertas para a Terceira Idade}

A educação surge como oportunidade para os idosos aperfeiçoarem e/ou adquirirem novos conhecimentos, uma vez que a maioria não teve condições de acesso ao ambiente universitário em outros momentos.

O papel político da educação passa a ser fundamental diante do papel eminentemente democrático que esta assume, por ser um lugar de encontro e de constante troca de experiências (Gadotti, 1984, p.157).

Mas a realidade mostra que os cidadãos idosos têm sua cidadania frequentemente violada, fazendo com que o ser humano seja desrespeitado em diferentes âmbitos. É nesse contexto que a educação se fortalece enquanto meio de libertação frente a marginalização.

\footnotetext{
Essencial também é lutar por uma efetiva democratização da educação, estendendo-a a todos, de modo a instrumentalizar os indivíduos com os conteúdos básicos valorizados pela sociedade, para que, uma vez dotados de instrumentos de acesso ao saber e de senso crítico, possam ter melhores condições de vida e de trabalho. (OLIVEIRA, 2001, p. 20)
}

Ao se refletir sobre a educação na terceira idade se destaca a importância da mesma especialmente no que se refere a um processo de aperfeiçoamento dos conhecimentos, aquisição de outros conforme interesses e necessidades, mas também se entende a educação como um meio de compreensão de si próprio, de suas limitações e possibilidades, de fortalecimento da autoestima e de melhoria na qualidade de vida. 


\section{Universidade do Extremo Sul Catarinense Revista Ibero-Americana de Humanidades, Ciências e Educação

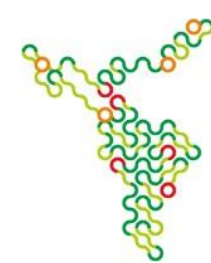

A educação permanente se apresenta como a necessidade de ampliar a participação dos indivíduos na vida social e cultural, visando à melhoria das relações interpessoais, qualidade de vida, compreendendo o mundo e tendo esperança de futuro. Pela educação permanente assume-se uma nova concepção de vida humana, cujo princípio central não é só aprender a ser, mas principalmente viver para aprender, interagindo com quem está ao seu redor. (OLIVEIRA; OLIVEIRA; SCORTEGAGNA, 2012, p. 87)

Ao entender o indivíduo tem a capacidade de aprender durante toda a sua vida, a educação permanente desponta como uma possibilidade real de alicerce na construção da sociedade que se deseja. Mesmo com a redução de algumas funções cognitivas ao longo da vida, o envelhecimento não restringe a capacidade de aprender nem a vontade de se construir a cada dia.

\footnotetext{
A educação constitui um processo em que cada ser humano aprende a se formar, a se informar a fim de transformar-se e transformar o mundo. O homem é um ser inacabado que tende à imperfeição; em consequência, a educação torna-se um processo contínuo que só termina com a morte. A educação não é apenas conservadora, porque assim aceitaria que a situação atual é ideal; porém, ela traz o germe da mudança, tornando-se, por isso, o instrumento de realização das utopias (OLIVEIRA, 1999, p.78)
}

Ao se abordar a educação permanente como um caminho para a libertação e empoderamento do idoso, se compreende que ela possibilitará ao sujeito aprender ao longo da vida, mesmo com o avanço da idade e independente da condição social. Ao realizar atividades que promovem alegria e satisfação os efeitos para a saúde são instantâneos por ativar o sistema de recompensa. As áreas cerebrais que estavam até então inativas, passam a corresponder positivamente.

A importância da educação permanente é ressaltada por Mosquera (1975, p.141) "a educação permanente é universal no seu caráter e essencial à completa democratização da aprendizagem, caracterizada pela sua flexibilidade e diversidade em conteúdos, apreendendo elementos, técnicas e finalidades abertas ao tempo e ao espaço".

A educação permanente se destaca nas Universidades Abertas para a Terceira Idade (UATI), fundamentando todas as ações educacionais voltadas aos idosos (Oliveira; Oliveira; Scortegagna, 2015, p.88). Ao estarem inseridos em um projeto que permite a participação efetiva na vida social e cultural, além da possibilidade de aquisição de novos conhecimentos, os idosos passam a se perceberem como parte integrante e atuante da sociedade.

Quando as instituições de ensino superior aderem a um projeto extensionista cujas ações refletem diretamente na comunidade em que estão inseridas, demonstram claramente um papel de responsabilidade social.

No Estatuto do Idoso (Lei 10741/03), que completa 15 anos no ano de 2018, está garantido no artigo 25 que o poder público deve apoiar a criação das universidades abertas, que possuem um cunho 


\section{Universidade do Extremo Sul Catarinense \\ Revista Ibero-Americana de Humanidades, Ciências e \\ Educação \\ unesc

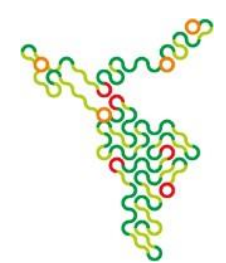

educacional e suas ações voltadas para os idosos deve promover, por meio da educação, a inclusão social do idoso e garantir sua cidadania.

Desde sua criação, na década de 1960, na França, a Universidade da Terceira Idade (UTA) visava promover o protagonismo da pessoa idosa, melhorar a qualidade de vida, abrir o ambiente universitário em prol da desconstrução da marginalização do idoso, além do aprofundamento das pesquisas em torno dos temas gerontológicos (Palma, 2000, p. 53).

Outra proposta diferenciada e que influenciou o modelo posteriormente desenvolvido no Brasil, é o modelo inglês, baseado no compartilhamento de conhecimentos, na relação de troca estabelecida entre professor e aluno e do destaque nas experiências intergeracionais.

\footnotetext{
O modelo inglês nasceu em Cambridge, em 1981, baseando-se no ideal de autoajuda. A certeza de que todos os especialistas de todas as áreas envelhecem e se aposentam norteou a criação de um espaço de troca, dentro das universidades, entre os mais velhos e os mais jovens (PACHECO, 2003, p. 224).
}

Tanto o modelo francês quanto o inglês foram influentes na criação das universidades para a terceira idade em todo o mundo. Mesmo com as peculiaridades de cada lugar, a ideia de oferecer espaços de aprendizado e integração geracional, além da valorização do idoso e possibilidade de construção de novos conhecimentos foi unânime. No Brasil não foi diferente. Com ações isoladas desde a década de 1970 e com a efetivação das UATI a partir de 1990 muitas universidades assumiram esse papel social com os idosos e com a sociedade "buscando integrar aqueles que se encontram à margem do processo de desenvolvimento" (Oliveira, 1999, p. 240).

\section{A Universidade Estadual de Ponta Grossa e a UATI}

No Estado do Paraná, a Universidade Estadual de Ponta Grossa foi a primeira a oferecer espaço para a Universidade Aberta para a Terceira Idade (UATI), no ano de 1992. O então projeto, realizado de forma ininterrupta desde aquele ano, foi transformado em programa no ano de 2012, diante dos benefícios trazidos para a comunidade e região dos Campos Gerais. Hoje, o Programa Universidade Aberta para a Terceira Idade é composto por dois cursos: a Universidade Aberta para a Terceira Idade (UATI) e a Universidade Continuada para a Terceira Idade (UCTI). O primeiro (UATI), possui duração de três semestres, organizados em disciplinas obrigatórias (teóricas) e práticas (a serem escolhidas pelo idoso); a segunda (UCTI), destina-se aos idosos que já integraram a UATI e desejam manter as atividades práticas e a participação nos projetos que o programa realiza. O diferencial de um projeto que se transformou em programa, com 27 anos de existência, com centenas de alunos envolvidos nas atividades propostas e sendo precursor no Estado dentro de sua área de 


\section{Universidade do Extremo Sul Catarinense \\ Revista Ibero-Americana de Humanidades, Ciências e \\ Educação \\ unesc \\ Produção e democratização do conhecimento na Ibero-América}

atuação, está especialmente na busca constante por desenvolver diferentes habilidades e competências em seu público-alvo, ampliando conhecimentos e aprimorando as relação intergeracionais, a troca de saberes, a inserção e a participação social dos idosos (Oliveira; Scortegagna; Oliveira, 2015, P. 92).

O programa, em sua diversidade de atividades, busca atingir idosos com diferentes idades, formação e necessidades. Com os levantamentos anuais é possível perceber tanto o crescimento do programa quanto o perfil dos alunos. Esses levantamentos fazem parte do acompanhamento do programa e oferecem dados que permitem, de certa maneira, avaliar o crescimento da UATI/UEPG.

Desde o ano de 1992, o programa já teve 1736 alunos matriculados, com 87 alunos (5,01\%) abaixo de 50 anos, 611 alunos (35,20\%) entre 51 e 60 anos, 785 alunos (45,21\%) entre 61 e 70 anos, 228 alunos $(13,14 \%)$ entre 71 e 80 anos e 25 alunos (1,44\%) acima de 81 anos (Tabela 1).

TABELA 1 - Faixa etária dos alunos matriculados no Programa da

Universidade Aberta para a Terceira Idade

\begin{tabular}{|c|c|c|c|c|c|c|c|}
\hline TURMA & ANO & $<50$ anos & $\begin{array}{c}51-60 \\
\text { anos }\end{array}$ & $\begin{array}{c}61-70 \\
\text { anos }\end{array}$ & $\begin{array}{c}71-80 \\
\text { anos }\end{array}$ & $>81$ anos & Total \\
\hline I & 1992 & 3 & 17 & 18 & 7 & 1 & 46 \\
\hline II & 1993 & 4 & 23 & 20 & 6 & 1 & 54 \\
\hline III & 1994 & 2 & 15 & 14 & 10 & 2 & 43 \\
\hline IV & 1995 & 8 & 11 & 15 & 4 & 0 & 38 \\
\hline V & 1996 & 4 & 16 & 27 & 6 & 0 & 53 \\
\hline VI & 1997 & 7 & 9 & 22 & 12 & 2 & 52 \\
\hline VII & 1998 & 5 & 25 & 17 & 2 & 0 & 49 \\
\hline VIII & 1999 & 3 & 11 & 30 & 5 & 1 & 50 \\
\hline IX & 2000 & 4 & 24 & 27 & 4 & 1 & 60 \\
\hline X & 2001 & 5 & 22 & 22 & 3 & 1 & 53 \\
\hline XI & 2002 & 5 & 17 & 14 & 19 & 0 & 55 \\
\hline XII & 2003 & 4 & 17 & 27 & 5 & 0 & 53 \\
\hline XIII & 2004 & 4 & 22 & 27 & 12 & 0 & 65 \\
\hline XIV & 2005 & 7 & 29 & 21 & 9 & 1 & 67 \\
\hline
\end{tabular}


Universidade do Extremo Sul Catarinense

Revista lbero-Americana de Humanidades, Ciências e

Educação

Unesc Produção e democratização do conhecimento na lbero-América

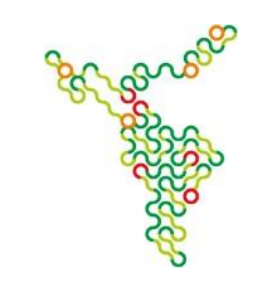

\begin{tabular}{|c|c|c|c|c|c|c|c|}
\hline XV & 2006 & 5 & 24 & 27 & 6 & 0 & 62 \\
\hline XVI & 2007 & 2 & 28 & 23 & 9 & 0 & 62 \\
\hline XVII & 2008 & 4 & 36 & 14 & 7 & 0 & 61 \\
\hline XVIII & 2009 & 2 & 27 & 27 & 10 & 4 & 70 \\
\hline XIX & 2010 & 1 & 28 & 28 & 11 & 5 & 73 \\
\hline XX & 2011 & 3 & 31 & 38 & 11 & 1 & 84 \\
\hline XXI & 2012 & 1 & 34 & 44 & 6 & 0 & 85 \\
\hline XXII & 2013 & 1 & 26 & 55 & 6 & 0 & 88 \\
\hline XXIII & 2014 & 0 & 25 & 43 & 11 & 0 & 79 \\
\hline XXIV & 2015 & 2 & 23 & 50 & 19 & 1 & 95 \\
\hline XXV & 2016 & 0 & 31 & 49 & 6 & 1 & 87 \\
\hline XXVI & 2017 & 0 & 16 & 38 & 13 & 2 & 69 \\
\hline XXVII & 2018 & 1 & 24 & 48 & 9 & 1 & 83 \\
\hline & Total & 87 & 611 & 785 & 228 & 25 & 1736 \\
\hline & Percentual & $5,01 \%$ & $35,20 \%$ & $45,21 \%$ & $13,14 \%$ & $1,44 \%$ & $100 \%$ \\
\hline
\end{tabular}

Fonte: Dados do arquivo do Programa da Universidade Aberta para a Terceira Idade.

Destaca-se a grande presença feminina (1590 idosas - 91,60\%) no Programa, fato especialmente explicado se analisarmos a literatura, que aponta a feminização da velhice como algo muito forte e presente em nossa sociedade.

Como resultado de uma desigualdade de gênero na expectativa de vida, existe essa proporção maior de mulheres do que de homens nesse grupo populacional. As mulheres vivem, em média, sete anos a mais do que os homens e estão vivendo mais do que nunca. Outra característica deste grupo populacional é que existe uma maior proporção de viúvas do que em qualquer outra faixa etária. Uma razão que poderia explicar essa situação é q eu, por tradição, a mulher tende a se casar com homens mais velhos do que ela, o que, associado a uma mortalidade masculina maior do que a feminina, aumenta a probabilidade de sobrevivência da mulher em relação ao seu cônjuge (SALGADO, 2002, p. 8).

Em relação à escolaridade dos idosos que integram a UATI/UEPG, 522 alunos (30,28\%) apresentam ensino fundamental incompleto, 259 alunos $(15,02 \%)$ apresentam ensino superior completo (Tabela 2). Esses dados comprovam que o Programa atinge uma população com conhecimento acadêmico diversificado. As atividades oferecidas buscam exatamente acolher e corresponder às expectativas dos idosos indiferentemente do grau de instrução dos mesmos. 
Universidade do Extremo Sul Catarinense

Revista lbero-Americana de Humanidades, Ciências e

Educação

Unesc Produção e democratização do conhecimento na lbero-América

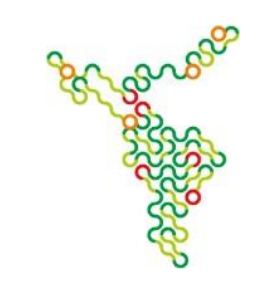

TABELA 2 - Escolaridade dos alunos matriculados no Programa Universidade Aberta para a

Terceira Idade

\begin{tabular}{|c|c|c|c|c|c|c|c|c|}
\hline & & \multicolumn{2}{c|}{$\begin{array}{c}\text { Ensino } \\
\text { Fundamental }\end{array}$} & \multicolumn{2}{c|}{$\begin{array}{c}\text { Ensino } \\
\text { Médio }\end{array}$} & \multicolumn{2}{c|}{$\begin{array}{c}\text { Ensino } \\
\text { Superior }\end{array}$} \\
\hline Turma & Ano & $\begin{array}{c}\text { EF } \\
\text { Compl. }\end{array}$ & $\begin{array}{c}\text { EF } \\
\text { Incompl. }\end{array}$ & EM Compl. & $\begin{array}{c}\text { EM } \\
\text { Incompl. }\end{array}$ & $\begin{array}{c}\text { ES } \\
\text { Compl. }\end{array}$ & $\begin{array}{c}\text { ES } \\
\text { Incompl. }\end{array}$ & Total \\
\hline I & 1992 & 9 & 15 & 9 & 2 & 7 & 4 & 46 \\
\hline II & 1993 & 12 & 7 & 24 & 0 & 10 & 1 & 54 \\
\hline III & 1994 & 10 & 22 & 12 & 0 & 2 & 0 & 46 \\
\hline IV & 1995 & 7 & 20 & 5 & 2 & 4 & 0 & 38 \\
\hline V & 1996 & 7 & 24 & 17 & 0 & 5 & 0 & 53 \\
\hline VI & 1997 & 5 & 38 & 7 & 0 & 2 & 0 & 52 \\
\hline VII & 1998 & 6 & 24 & 14 & 0 & 5 & 0 & 49 \\
\hline VIII & 1999 & 9 & 28 & 9 & 0 & 4 & 0 & 50 \\
\hline IX & 2000 & 11 & 22 & 22 & 0 & 3 & 0 & 58 \\
\hline X & 2001 & 18 & 21 & 8 & 0 & 4 & 1 & 52 \\
\hline XI & 2002 & 17 & 23 & 9 & 0 & 6 & 0 & 55 \\
\hline XII & 2003 & 16 & 23 & 5 & 1 & 8 & 0 & 53 \\
\hline XIII & 2004 & 15 & 24 & 16 & 0 & 9 & 1 & 65 \\
\hline XIV & 2005 & 14 & 16 & 15 & 11 & 10 & 1 & 67 \\
\hline XV & 2006 & 9 & 16 & 26 & 0 & 11 & 0 & 62 \\
\hline XVI & 2007 & 13 & 17 & 25 & 0 & 7 & 1 & 63 \\
\hline XVII & 2008 & 15 & 19 & 18 & 0 & 8 & 1 & 61 \\
\hline XVIII & 2009 & 12 & 18 & 4 & 24 & 12 & 0 & 70 \\
\hline XIX & 2010 & 9 & 22 & 8 & 22 & 11 & 1 & 73 \\
\hline XX & 2011 & 9 & 25 & 11 & 29 & 10 & 0 & 84 \\
\hline XXI & 2012 & 12 & 20 & 33 & 0 & 20 & 0 & 85 \\
\hline XXII & 2013 & 1 & 26 & 26 & 0 & 22 & 0 & 75 \\
\hline XXIII & 2014 & 14 & 22 & 26 & 1 & 16 & 0 & 79 \\
\hline XXIV & 2015 & 24 & 10 & 45 & 5 & 9 & 2 & 95 \\
\hline XXV & 2016 & 18 & 6 & 35 & 5 & 20 & 3 & 87 \\
\hline XXVI & 2017 & 19 & 5 & 30 & 0 & 14 & 1 & 69 \\
\hline XXVII & 2018 & 22 & 9 & 28 & 1 & 20 & 3 & 83 \\
\hline & Total & 333 & 522 & 487 & 103 & 259 & 20 & 1724 \\
\hline & Percentual & $19,31 \%$ & $30,28 \%$ & $28,25 \%$ & $5,98 \%$ & $15,02 \%$ & $1,16 \%$ & $100 \%$ \\
\hline
\end{tabular}

Fonte: Dados do arquivo do Programa da Universidade Aberta para a Terceira Idade.

\section{Considerações finais}

As ações desenvolvidas pelas Universidades Abertas para a Terceira Idade possuem um caráter social indiscutível, uma vez que reforçam o desenvolvimento, a participação cidadã, priorizam o aprendizado e a melhoria da qualidade de vida. Ao propiciar o empoderamento dos idosos (em relação a maior confiança nas capacidades pessoais e a ampliação das relações afetivas), passam a ressignificar os sentidos dados à própria vida.

Com a presença na comunidade universitária, o idoso tem a possibilidade de entrar em contato com indivíduos de outras gerações e enriquecer discussões acerca de assuntos diversos, que interessam a todos os cidadãos, vencem as barreiras de discriminações, passando a fortalecer relações

Revista Ibero-Americana de Humanidades, Ciências e Educação. Criciúma, v.6.n.1, 2020. 


\section{Universidade do Extremo Sul Catarinense \\ Revista Ibero-Americana de Humanidades, Ciências e \\ Educação \\ unesc

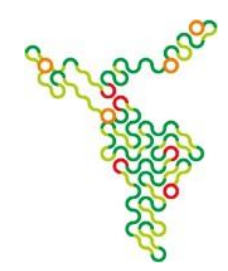

intergeracionais e contribuir com os mais jovens, pois os idosos possuem muitos conhecimentos a serem transmitidos as demais gerações.

O Programa da UATI/UEPG se fortalece e se renova a cada ano, oferecendo diferentes atividades e desenvolvendo projetos que são um diferencial para a comunidade. $O$ número crescente de idosos, ano após ano, reforça que os objetivos propostos desde 1992 têm sido atingidos. Os idosos chegam a UATI/UEPG buscando conhecimentos, atualizações, informações, integração e participação social. Com as atividades e projetos desenvolvidos eles tem a oportunidade de encontrar realização e acolhimento, tanto por parte da Universidade como pela comunidade como um todo.

Diante das atividades desenvolvidas pela UATI/UEPG fica evidente a importância de políticas públicas voltadas aos idosos em todas as áreas. As políticas educacionais também precisam de aperfeiçoamento, para que os profissionais que desenvolvem as mais variadas atividades com os idosos possam ter formação adequada, desenvolver metodologias e conteúdos coerentes com as necessidades e interesses desses indivíduos. Todas as ações concretas que valorizem o idoso, que possam proporcionar a ele maior qualidade de vida e respeito, necessitam de efetivação. Se o jovem é o futuro de uma nação, o idoso é parte de sua história. E não existe futuro sem respeito ao passado.

\section{Referências}

BRASIL. Lei n. 10741 de 1 de outubro de 2003. Dispõe sobre o Estatuto do Idoso. Brasília, 2003.

GADOTTI, M. A educação contra a educação. Rio de Janeiro: Paz e Terra, 1984.

IBGE. Expectativa de vida dos brasileiros. 2017. Disponível em: https://agenciadenoticias.ibge.gov.br/agencia-noticias/2012-agencia-de-noticias/noticias/18469expectativa-de-vida-do-brasileiro-sobe-para-75-8-anos.html. Acesso em: 15 de fevereiro de 2018.

MOSQUERA, J. J. M. Educação: novas perspectivas. Porto Alegre: Sulina, 1975.

OLIVEIRA, R. C. S. Terceira idade: do repensar dos limites aos sonhos possíveis. São Paulo: Papirus, 1999.

Docência para a terceira idade. Olhar do professor, Ponta Grossa, v.4, n.1, p. 21 -

32, 2001. 


\section{Universidade do Extremo Sul Catarinense \\ Revista Ibero-Americana de Humanidades, Ciências e \\ Educação \\ Unesc Produção e democratização do conhecimento na lbero-América}

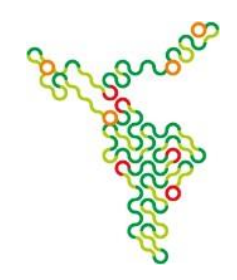

Velhice: teorias, conceitos e preconceitos. A terceira idade, São Paulo, v.12, n.25, p.37-52, ago./2002.

OLIVEIRA, R. C. S.; OLIVEIRA, F. S.; SCORTEGAGNA, P. A. Universidade Aberta para a Terceira Idade: a extensão como meio de inserção do idoso no contexto universitário. Assis: Storbem, 2012.

PACHECO, J. L. As universidades abertas à terceira idade como espaço de convivência entre gerações. In: SIMSON, O. R. M. V.; NERI, A. L.; CACHIONI, M. (Orgs). As múltiplas faces da velhice no Brasil. Campinas: Alínea, 2003.

PALMA, L. T. S. Educação permanente e qualidade de vida: indicativos para uma velhice bemsucedida. Passo Fundo: UPF, 2000.B

SALGADO, C. D. Mulher idosa: a feminização da velhice. In: Estudos Interdisciplinares sobre o envelhecimento. Porto Alegre, v.4, p.7-19, 2002.

SANTIN, J. R.; BETTINELLI, L. A.; BENINCÁ, C. R. (org). Envelhecimento humano: cuidado e cidadania. Passo Fundo: Universidade de Passo Fundo, 2007.

TAAM, R. A educação não formal do idoso em universidades da terceira idade e centros de convivencia. In: Educação e velhice. Holambra: Setembro, 2009. 